Background The role of polymorphonuclear cells in the development of a chronic inflammatory process still remains controversial. Neutrophilic granules comprise various biologically active proteins, which play a pathogenic role in the development of chronic auto-immune diseases, such as rheumatoid arthritis. Elastase - a marker of primary granules, being a factor of protection in healthy individuals, may exert a pro-inflammatory effect in rheumatoid arthritis, promoting the degradation of the cartilage matrix and the activation of proteolytic enzymes. The constituent of secondary neutrophilic granules - lactoferrin - a $77 \mathrm{kDa}$ protein with certain anti-microbal and anti-inflammatory properties.

Objectives To evaluate the role of constituents of neutrophilic granules ? lactoferrin and elastase ? in the pathogenesis of rheumatoid arthritis.

Methods In this study the serum levels of elastase and lactoferrin and an immunohistochemical staining reaction of polymorphonuclear cells for lactoferrin were assessed in 70 patients with rheumatoid arthritis.

Results The serum level of elastase - a marker of neutrophils' activation - was dramatically increased in patients with rheumatoid arthritis in comparison to healthy persons ( $p<0.001$ ). However, the serum level of lactoferrin was significantly decreased in patients with rheumatoid arthritis (195.5 \pm 11.7 $\mathrm{ng} / \mathrm{ml}$ vs. $626.9 \pm 20.8 \mathrm{ng} / \mathrm{ml}$ in healthy donors; $\mathrm{p}<0.001)$. Blood neutrophils displayed weak staining for lactoferrin in rheumatoid arthritis. The decrease of serum level of lactoferrin and its concentration in polymorphonuclear cells was greater in patients who were diagnosed with extra-articular manifestations, such as rheumatoid nodules and Felty's syndrome $(\mathrm{p}<0.05)$. These patients also had greater serum level of elastase. The serum level of lactoferrin didn't depend on the presence or absence of a rheumatoid factor or on the intensity of radiographic changes, but it inversely correlated with the serum levels of elastase, IgA, IgG, C-reactive protein and erythrocyte sedimentation rate. Treatment with non-steroidal anti-inflammatory drugs resulted in a clinical amelioration and was accompanied by the decrease of serum elastase level $(\mathrm{p}<0.01)$. The serum level of lactoferrin was slightly raised after treatment $(\mathrm{p}<0.05)$, which we consider to be a secondary effect due to decreased lactoferrin consumption. However, the intensity of neutrophilic staining reaction for lactoferrin remained unchanged.

Conclusion These data suggest a dysfunction of polymorphonuclear cells in rheumatoid arthritis: active synthesis and secretion of elastase is accompanied by the decreased synthesis of lactoferrin. The deficiency of lactoferrin - a potent antioxidant - may contribute to disease activity and the development of extra-articular manifestation in rheumatoid arthritis. The mechanism of this deficiency still remains unclear.

\section{THU0074 VITAMIN E UNCOUPLES JOINT INFLAMMATION AND ARTICULAR DESTRUCTION, IN A TRANSGENIC MOUSE MODEL OF RHEUMATOID ARTHRITIS}

${ }^{1} \mathrm{MJ}$ De Bandt, ${ }^{1} \mathrm{~F}$ Driss, ${ }^{1} \mathrm{M}$ Grossin, ${ }^{2} \mathrm{~J}$ Pincemail, ${ }^{1} \mathrm{C}$ Babin-Chevaye, ${ }^{3} \mathrm{C}$ Gaertner, ${ }^{1} \mathrm{C}$ Pasquier. IINSERM U 479, Bichat, Paris, France; ${ }^{2} \mathrm{CHU}$ de Liège, Domaine Du Start Tilman, Liège, Belgique; ${ }^{3}$ COGNIS, Dusseldorf, Deutschland

\subsection{6/annrheumdis-2001.951}

Background Reactive oxygen species (ROS) are suspected to play a role in human RA. Transient hypoxia and ischaemic-reperfusion phenomenon are involved in their chronic production, by monocytes and macrophages. Nevertheless the clinical interest of ROS scavengers is difficult to evaluate.

Objectives

Methods We studied the effects of Vitamin E (natural alpha tocopherol) on transgenic KRN/NOD mice, new model for rheumatoid arthritis. We determined clinical, histological and biochemical parameters so as to define the long-term benefit of Vitamin E in the disease.

Results We found an increase in plasma Vit E, in treated mice. Vitamin $\mathrm{E}$ treatment did not modify the date of onset of the disease, neither the intensity of the disease (arthritic index and weight), but Vit-E prevented from articular destruction, suggesting uncoupling of the two phenomenon. Biochemical analysis, blood glutathion, urine isoprostane and the plasma hydroperoxide did not differ between Vit E-treated transgenic KRN/NOD mice and control mice. Blood chemiluminescence was increased in transgenic KRN/NOD mice as compared to non-transgenic mice, and was decreased in Vit E-treated transgenic KRN/NOD mice. TNF-a and IL1-b, low in control non-transgenic mice, were increased in transgenic KRN/NOD mice, however a significant decreased in IL-1b appeared in Vit E-treated mice.

Conclusion These results suggest that ROS scavengers can modulate cytokines responses and provide new arguments for the interest of ROS scavengers in RA therapy.

\section{THU0075 MYCOPLASMA PNEUMONIAE INFECTION AND RHEUMATOID ARTHRITIS}

AS Ramirez-Corbera, JA Hernández-Beriain, A Rosas, E Girona. Rheumatology Section, Hospital Insular de GC, Las Palmas de GC, Spain

10.1136/annrheumdis-2001.952

Background An infective aetiology for rheumatoid arthritis (RA) has often been postulated. Thirteen species of mycoplasmas has been implicated in the origin of arthritis in experimental models and animals. Fragments of mycoplasma (PCR) has been detected in RA although the results are conflictive.

Objectives The main of our work is to evaluate previous mycoplasma pneumoniae (MP) infection in a cohort of RA outpatients and further evaluation of MP infection and RA outcome.

Methods In 80 RA patients IgG antiMP was evaluated with ELISA. RA was evaluated according to disease duration, RF status and radiological stage. In control group were included 150 healthy people. Statistical analysis included Kruskal-Wallis test for IgG levels and determination of relative risk (odds ratio).

Results Mean age of RA patients was 53.17 (22-81 years); 83\% were females. MP serology was positive in 54\% of RA patients and $31 \%$ of controls $(\mathrm{p}<0.05)$. Medium level of IgG was 1.431 in RA patients and 0.87 in controls $(\mathrm{p}<0.0001)$. Previous MP infection conditioned a relative risk (odds ratio) for RA of 3.22 (95 CI; 1.76-5.91).

Conclusion Previous MP infection was more frequent in RA patients than controls. MP infection could play a role in RA genesis. 


\section{THU0076 ADENOVIRUS MEDIATED GENE TRANSFER OF UROKINASE PLASMINOGEN INHIBITOR INHIBITS ANGIOGENESIS IN EXPERIMENTAL ARTHRITIS}

C Jorgensen, F Apparailly, C Bouquet, V Millet, D Noel, P Yeh, J Sany. ImmunoRheumatology, Lapeyronie, Montpellier, France

\subsection{6/annrheumdis-2001.953}

Background Plasmin is essential for metalloproteases (MMP) activation, endothelial cell migration and degradation of the extracellular matrix. The process is common to neoangiogenesis and pannus formation, and $80 \%$ of synovial cells express urokinase plasminogen activator receptor (UPAR).

Objectives We inhibited plasmin activation by expressing uPA/ uPAR antagonist chimeric molecule (ATF-HSA) through adenoviral mediated gene transfer in experimental arthritis.

Methods Overexpression of ATF-HSA was obtained by IV injection of 109 pfu of a non replicative E1 deleted type 5 adenoviral vector containing murine ATF gene linked to HSA gene under the control of a CMV promoter. Collagen-induced arthritis (CIA) was obtained by immunisation of DBA1 mice with bovine type II collagen in FCA. AdATF-HSA was injected IV on day 25 after immunisation. On day 44, X ray and Immuno-histology of paws were performed. The SCID/hu model was used to assess the effect of adenoviral mediated huATF gene transfer on human rheumatoid synovium angiogenesis.

Results

Conclusion The uPAR antagonist ATF-HSA is a new tool for gene therapy in arthritis. The preventive effect observed may be related to the decrease in angiogenesis rather than inhibition of extracellular matrix degradation.

\section{THU0077 INTERATIONS BETWEEN INFLAMMATORY POLYARTHRITIS AND CARDIOVASCULAR DISEASE}

${ }^{1} \mathrm{PH}$ Dessein, ${ }^{1} \mathrm{AE}$ Stanwix, ${ }^{2} \mathrm{BI}$ Joffe, ${ }^{3} \mathrm{EA}$ Shipton. ${ }^{1}$ Rheumatology; ${ }^{2}$ Carbohydrate and Lipid Metabolism Research Unit; ${ }^{3}$ Pain Relief and Research Unit, CH Baragwanath Hospital, Johannesburg, South Africa

\subsection{6/annrheumdis-2001.954}

Background Inflammatory polyarthritis (IP) and cardiovascular disease (CVD) may share a common predisposition and disease activity in IP may be complicated by worsening of CVD risk factors profiles.

Objectives The aim of the present study was to provide evidence for these hypotheses.

Methods A literature search on predisposing factors for IP and a case controlled study in 87 IP patients (38 rheumatoid arthritis, 29 spondyloarthropathy and 20 undifferentiated inflammatory arthritis) on CVD risk factors were performed.

Results Recently identified predisposing factors for IP bear remarkable similarities to CVD risk factors. They include ageing, obesity, smoking, elevated cholesterol and apolipoprotein (apo) (a) concentrations, subtle hypoadrenalism, decreased unsaturated fat intake and antioxidant concentrations, no alcohol intake, infections and stressful life events. Indeed, activation of nuclear factor kappa B, monoclonal expansion of proinflammatory $\mathrm{CD} 4{ }^{+} \mathrm{CD} 28-\mathrm{T}$ cells and acute phase responses (APR), the mutually reinforcing relationship between obesity/insulin resistance (IR) and hypoadrenalism and, endothelial dysfunction may each play a pivotal role in both IP and CVD. In established IP, disease activity associates with the presence of APR, raised apo (a), cholesterol/HDL-cholesterol and apo B/A1 ratios, IR and decreased dehydroepiandrosterone sulphate (DHEAS) concentrations, thereby worsening CVD risk factor profiles. Three studies reported a $60-80 \%$ excess CVD mortality in rheumatoid arthritis. In a more recent investigation, in which disease modifying agents were instituted soon after disease onset, the 10 year survival was similar to the general population. In our controlled study, IP was associated with a positive family history for coronary artery disease $(\mathrm{p}<0.03)$. Twenty five $(29 \%)$ patients had IR and this could be accounted for by the APR and body mass index (BMI). Cholesterol/HDL-cholesterol ratios were elevated and this was only partially attributable to the APR, BMI and IR. Twenty four (28\%) patients had decreased DHEAS concentrations and in women, this could not be fully explained by the APR, IR, disease duration, previous glucocorticoid and current NSAID usage.

Conclusion Further elucidation of etiopathogenetic mechanisms shared by IP and CVD may yield more effective therapies for both conditions. Meanwhile, CVD risk factor profiles should be addressed in IP management.

\section{REFERENCES}

1 Dessein $\mathrm{PH}$, et al. Rheumatology 2001, in press

2 Liuzzo G, et al. Circulation 2000;102: 2883-8

3 Weyand CM, et al. Arch Immunol Ther Exp (Warsz) 2000;48:429-35

4 Kroot EJ, et al. Ann Rheum Dis. 2000;59:954-8

\section{THU0078 ANTIARTHRITIC EFFECT OF SALBUTAMOL ALONE AND IN COMBINATION WITH PENTOXYPHILINE ON ADJUVANT ARTHRITIS IN RATS}

R Bradunaite, E Bernotiene, L Leonaviciene, D Vaitkiene. Laboratory of Experimental Pathology, Institute of Experimental and Clinical Medicine, Vilnius, Lithuania

\subsection{6/annrheumdis-2001.955}

Background The beta-2 ?adrenergic agonist salbutamol (S) and the phosphodiesterase inhibitor pentoxifylline $(\mathrm{P})$ are reported to be the elevators of cAMP and the suppressors of Th1 response. $^{1,2}$ Elevation of intracellular cAMP reduces the production of IL-12 and TNF, the important cytokines in the pathogenesis of rheumathoid arthritis (RA).

Objectives To evaluate the antiarthritic effect of $S$ alone and in combination with $\mathrm{P}$ on the model of $\mathrm{RA}$ in animals - the expressed adjuvant arthritis (AA) in rats.

Methods Experiment was performed on 30 female Lewis rats with AA induced by a single subplantar injection of $0,1 \mathrm{ml}$ of complete Freud's adjuvant into the left hind paw. On day 8 of experiment, rats were assigned into 3 groups with the similar mean scores of joint swelling and the treatment with $S$ (1st group) and $\mathrm{S}+\mathrm{P}$ (2nd) was started. Control group (3rd) received $1 \mathrm{ml}$ of starch gel. Drugs were prepared as the suspension in $1 \%$ starch gel and administered intragastrically 5 times a week in a volume of $1 \mathrm{ml}$ in following doses: $\mathrm{S}$ ? $8,5 \mathrm{mg} / \mathrm{kg}$ and $\mathrm{P}$ ? 500 $\mathrm{mg} / \mathrm{kg}$. The duration of treatment ? 2 weeks. Body weight and joint swelling were monitored 3 times a week. Haematological and pathomorphological changes were evaluated at the end of experiment (day 23).

Results $S$ significantly $(\mathrm{p}<0,02)$ reduced joint swelling by $38,3 \%$ at the end of experiment. Combined treatment with $\mathrm{S}+\mathrm{P}$ was more effective and significantly $(\mathrm{p}<0,02-0,01)$ diminished joint swelling starting at day 18 (by 36\%) till the end of experiment (by 44\%). Polyarthritis developed in $70 \%$ of animals treated with S, $60 \%$ - with S+P and $90 \%$ - of control group. The marked improvement $(\mathrm{p}<0,02)$ of blood indices was 